\title{
INTENSITY MEASURES FOR THE SEISMIC RESPONSE OF PILE
}

\section{FOUNDATIONS}

\author{
Brendon A Bradley", Misko Cubrinovski, Rajesh P Dhakal, Gregory A MacRae. \\ Department of Civil Engineering, University of Canterbury, Private Bag 4800, Christchurch 8020, New Zealand \\ *Corresponding author: $\mathrm{Ph}+64-3-3667001$ ext 7673; Fax: +64-3-364 2758; \\ Email: bab54@student.canterbury.ac.nz
}

\begin{abstract}
In this study the efficacy of various ground motion intensity measures for the seismic response of pile foundations embedded in liquefiable and non-liquefiable soils is investigated. A soil-pile-structure model consisting of a two-layer soil deposit with a single pile and a single degree-of-freedom superstructure is used in a parametric study to determine the salient features of the seismic response of the soil-pile-structure system. A suite of ground motion records scaled to various levels of intensity are used to investigate the full range of pile behaviour, from elastic response to failure. Various intensity measures are used to inspect their efficiency in predicting the seismic demand on the pile foundation for a given level of ground motion intensity. It is found that velocity-based intensity measures are the most efficient in predicting the pile response, which is measured in terms of maximum curvature or pile-head displacement. In particular, velocity spectrum intensity (VSI), which represents the integral of the pseudo-velocity spectrum over a wide period range, is found to be the most efficient intensity measure in predicting the seismic demands on the pile foundation. $V S I$ is also found to be a sufficient intensity measure with respect to earthquake magnitude, sourceto-site distance, and epsilon, and has a good predictability, thus making it a prime candidate for use in seismic response analysis of pile foundations.
\end{abstract}




\section{KEYWORDS}

Performance-based earthquake engineering (PBEE); velocity spectrum intensity (VSI); pile foundation; intensity measure (IM); engineering demand parameter (EDP); soil-structure interaction (SSI).

\section{INTRODUCTION}

In recent strong earthquakes, a large number of pile foundations of high-rise buildings, bridge piers and storage tanks have been severely damaged, thus affecting the functionality of modern engineering structures designed according to the most advanced seismic standards $[1$, 2]. The soil-pile-structure interaction during strong ground shaking is a complex phenomenon involving a significant change in stiffness and strength of soils and large lateral loads on piles. Both inertial loads from vibration of the superstructure and kinematic loads imposed by lateral ground displacements contribute toward pile damage. In the 1995 Kobe earthquake, for example, piles in non-liquefied deposits were subjected to peak cyclic ground displacements of about $30 \mathrm{~cm}$ whereas the respective displacements in liquefied soils reached about 40$50 \mathrm{~cm}$ causing damage to numerous pile foundations $[3,4]$. When evaluating the seismic performance of pile foundations, one should estimate the inelastic response of piles with the ultimate goal being the assessment of the potential damage to the foundation and consequent effects on the safety and functionality of the superstructure.

Rigorous seismic assessment of pile foundations (and their superstructures) requires the use of a probabilistic framework to account for the numerous uncertainties in quantifying the performance. Contemporary performance-based earthquake engineering (PBEE) evaluation is typically defined based on the PEER performance assessment methodology $[5,6]$ and consists of four key steps, as outlined schematically in Figure 1: ground motion estimation, seismic response estimation, damage estimation and loss estimation. Each of these four steps is linked 
together through the use of intensity measures (IM's), engineering demand parameters (EDP's) and damage measures (DM's) to give metrics of seismic performance, termed decision variables (DV's). When applied to a given structure, the methodology allows a probabilistic quantification of seismic performance using measures such as: annual rate of collapse, expected annual loss and annual rate of exceeding some economic loss, all of which can be easily communicated to decision makers and society.

Step 1 of the PEER methodology as given in Figure 1 is the use of a ground motion IM to provide a (probabilistic) relationship between the ground motion hazard at the site and the resulting seismic response. Clearly, the determination of seismic demands on piles (and structures in general) during strong ground motion is burdened by significant uncertainties. Such uncertainties may be either aleatory (randomness) or epistemic (knowledge-based) in nature. Obviously, one endeavours to minimise such uncertainties in order to improve system reliability and reduce seismic risk. Record-to-record (RTR) randomness (i.e. variation in seismic demand due to different ground motions of the same intensity) is a key uncertainty in the relationship between seismic demand and seismic intensity [7]. RTR randomness results from the complex mechanism of source rupture, wave propagation and scattering, local site and soil-structure interaction effects, as well as quantifying the ground motion shaking using a scalar or vector IM. It is therefore necessary to identify IMs which display a good correlation with the performance metric to be evaluated, thus reducing this uncertainty.

In this paper intensity measures for the seismic response of pile foundations embedded in both liquefiable and non-liquefiable soils is investigated. Nonlinear dynamic analyses of a soil-pile-structure model are used to identify the most appropriate EDP and IM for pile foundations. Firstly, consideration is given to the determination of an effective EDP that describes the seismic response of the pile and its associated damage. Next, various candidate IMs are examined and ranked based on their resulting aleatory uncertainty in predicting EDP 
(i.e. efficiency [8]); their response prediction independence on conventional measures of ground motion (i.e. sufficiency [9]); and the uncertainty in predicting the IM itself (i.e. predictability [10]). Demand hazard curves are used to illustrate the benefits of appropriately selecting IMs. Finally, effects of soil-pile-structure interaction and liquefaction on the deformation mechanism of the system are also discussed.

\section{ADOPTED SOIL-PILE-STRUCTURE MODEL}

A conceptually simplified numerical model is adopted in this investigation to adequately capture the salient features of the pile response without onerous complexity. As shown schematically in Figure 2a the model consists of a two-layer non-liquefiable soil deposit with a single pile, rigid pile cap and a superstructure represented by a single degreeof-freedom. To investigate the effects of different material and geometrical properties, six different scenarios are considered as summarised in Figure $2 b$ (herein for brevity ' $S$ ' will be used as shorthand notation for 'scenario'). S1-S4 involve variations of soil stiffness and strength, pile properties, weight and period of the superstructure, all of which are based on typically observed configurations in engineering practice. S5 and S6 are the same as S1 and S3, respectively, but with no superstructure in the FE model. S5 and S6 therefore represent cases where the response of the pile is entirely due to kinematic effects of the imposed ground deformations, without inertial effects from the superstructure vibration.

For each of the scenarios, the weight of the SDOF superstructure (in the FE model) was based on a typical axial load applied to a single pile within a pile group of a representative superstructure. The stiffness of the SDOF superstructure was then computed to achieve the same target period as that of the representative superstructure. A rigid pile cap with a width of $3 \mathrm{~m}$ was modelled using an elastic beam element with a large stiffness that effectively provided a 'fixed' condition at the head of the pile. The FE code DIANA-J [11] was used in 
the analyses, which allows for fully coupled effective-stress analysis of the soil medium capturing pore water pressure development, its redistribution and dissipation. An elasticplastic constitutive model for sand, the Stress-Density (S-D) model [12, 13] was used for modelling the soil behaviour. Two series of analyses were performed. In the first series, seismic analyses of the scenarios given in Figure $2 \mathrm{~b}$ were performed with the S-D model parameters set such that pore-pressure build-up is effectively suppressed to simulate nonliquefiable soil. In the second series of analyses, the effects of excess pore water pressures and eventual liquefaction were considered. The S-D model has been extensively verified through rigorous simulations of down-hole array records at liquefaction sites, seismic centrifuge tests, large-scale shake-table tests on pile foundations and case histories of damaged piles in the 1995 Kobe earthquake (e.g. [14] and references therein).

Conventional shear modulus reduction curves for sand proposed by Seed and Idriss [15] were used to determine model parameters controlling the nonlinear stress-strain behaviour of the soil (Figure $2 \mathrm{c}$ ). Figure $2 \mathrm{~d}$ illustrates the adopted liquefaction resistance curves for the two different soil layers considered. The cyclic stress ratio (CSR) at 20 cycles for the $N^{(1)}=10$ and $N^{(1)}=20$ soils were 0.15 and 0.26 , respectively. Dilatancy parameters of the constitutive model used in the analyses were based on those of Toyoura sand [13] and then modified to achieve the liquefaction resistance depicted in Figure 2d.

The pile was modelled using one-dimensional beam elements with a hyperbolic moment-curvature relationship as an approximation to the $M-\phi$ relationship obtained from fibre-based section analyses (Figure 2e; Table 1). Similarly, nonlinear beam elements with stiffness and mass defined by the parameters shown in Figure $2 b$ were used to model the superstructure. 


\section{GROUND MOTIONS AND INTENSITY MEASURES INVESTIGATED}

A suite of 40 ground motion records compiled by Medina and Krawinkler [16] were used as input motions in the nonlinear time history analyses. This suite contains ground motions recorded on stiff soils with magnitude and distance ranges of $M_{w}=6.5-6.9$ and $R=13.3-39.3 \mathrm{~km}$, respectively. The suite is termed 'ordinary' by Medina and Krawinkler, as none of the records show effects of near-fault motions (i.e. directivity or 'fling' effects), and all ground motions were recorded on stiff soils. In the series of analyses with non-liquefiable soils the FE model was subjected to a base input motion scaled to ten different levels of peak ground accelerations between 0.1 and $1.0 \mathrm{~g}$ in steps of $0.1 \mathrm{~g}$. In the series of analyses with liquefiable soils the input motions were scaled from $0.05 \mathrm{~g}$ to $0.5 \mathrm{~g}$ in steps of $0.05 \mathrm{~g}$. The smaller intensity increments for liquefiable soils were used to follow the extent of liquefaction with intensity more accurately. Thus, using the 40 different ground motion records as input motions, a total of 400 analyses were performed for each of the six scenarios listed in Figure $2 \mathrm{~b}$ (for both liquefiable and non-liquefiable analyses).

Significant research over the past decade has focused on determining optimal IMs for predicting structural response due to earthquake excitation (e.g. $[8,9,17,18]$ ). Clearly, different ground motion parameters should be used as IMs depending on the governing deformation mechanisms and response characteristics of the structure considered. Since pile foundations involve both kinematic and inertial effects due to soil and superstructure response, respectively, it is necessary to examine a wide range of potential IMs and identify the optimum IM for prediction of the pile response. The determination of an optimal IM for prediction of a level of seismic demand is guided by the concepts of 'efficiency' [8], 'sufficiency' [9], and 'predictability' [10]. Efficiency is related to the aleatory uncertainty in the EDP|IM relationship; sufficiency to the independence of the response to ground motion selection; and predictability to the uncertainty in predicting the ground motion IM using a 
ground motion prediction equation.

A total of 19 different IMs are considered for correlation with the pile response and are summarised in Table 2. All IMs were computed from the base input ground motion and IM definitions can be found in Riddell [19]. The investigated IMs include acceleration-, velocity, and displacement-based ground motion intensity measures, both of peak and cumulative nature.

It is well known that the destructive potential of a ground motion is dependent on its intensity, frequency content and duration. Thus, each of the ground motion IMs presented in Table 2 quantifies some or all of these characteristics of the ground motion. For example, peak quantities such as $P G A, P G V$ and peak ground displacement $(P G D)$ account for the ground motion intensity only. Spectral acceleration terms account for ground motion intensity at a specific period of vibration, while $A S I$ and $V S I$ account for the spectral quantities over a relevant range of vibration periods. $C A V$ accounts for both intensity and duration, while Arias intensity, $I_{a}$, accounts for all three ground motion characteristics. It is worth noting that the spectral acceleration IMs at periods of 0.8 and $1.8 \mathrm{~s}$ are selected to coincide with the firstmode period of the superstructure considered.

\section{MEASURE OF SEISMIC DEMAND ON PILES}

The first question to be answered before determining which ground motion IMs correlate well with seismic demand on piles is: how is the seismic demand measured? Ideally, the adopted EDP would correlate perfectly with the occurrence of damage in the pile. In comparison to the research attention that the EDP|IM relationship has received, little research has focused on determining optimal EDPs which correlate well with damage measures (DMs) in structural components and pile foundations in particular.

As with any engineering material, the seismic demand on a pile foundation is generally 
related to the hysteretic energy that is dissipated during ground motion excitation. Hysteretic energy is typically expressed as a function of both peak and cumulative deformations, one typical example being the damage index of Park and Ang [20]. However, due to the difficulty of developing fragility relationships between complex EDPs and damage in components, simple measures of demand are typically adopted. In the performance-based assessment of structural systems, typical EDPs used are cumulative plastic rotation and peak interstorey drift $[8,21]$. For simplicity, only peak response quantities will be used to quantify the seismic demand on the pile foundation in this study.

The peak pile curvature, $\phi_{p}$, would seem the most obvious candidate to use for pile demand, as it directly relates to the peak strains at the critical section of the pile and hence the extent of damage. However, peak pile curvature, being a localised measure of demand, is not easily related to the global response of the pile and the foundation system. The peak lateral displacement of the pile head (i.e. at the pile cap), $U_{p h}$, is such an EDP which represents the global response of the foundation. In addition, the peak foundation displacement can be used as a proxy for damage to connections, and post-earthquake serviceability of relevant lifelines (e.g. electricity and water piping).

It is intuitive that the peak pile-head displacement and the peak pile curvature are correlated based on the typical deformation pattern of piles caused by earthquake-induced lateral loads. Figure 3 illustrates the correlation between peak pile displacement, $U_{p h}$, and peak pile curvature, $\phi_{p}$, obtained from the 400 nonlinear finite element analyses on nonliquefiable soils for S1, S3, S5, and S6 as described in previous section. Here, each symbol represents the result of one analysis while the lines are best fit approximations of the trend. Note that the results of S2 and S4 are not shown here as they are similar to S1 and S3, respectively. Curvature results presented here have been obtained from the difference in the nodal rotations in the beam elements and were not found to be sensitive to the element length 
used (which was constant in all analyses). Figure $3 \mathrm{a}$ and $3 \mathrm{~b}$ illustrate that the correlation for $\mathrm{S} 3$ is not as strong as that for S1. Note that the difference between $\mathrm{S} 1$ and $\mathrm{S} 3$ is in the dynamic characteristics of the superstructure and pile properties. S5 and S6 are the same as S1 and S3, respectively, but with no superstructure, and both show good correlation between the pile curvature and pile-head displacement. The good correlation for S5 and S6 (the only difference between the scenarios being the properties of the pile) indicates that the relatively poor correlation for S3 cannot be explained by the pile properties or its flexibility. Therefore, the reduction in the correlation between curvature and pile-head displacement for S3 (and S4 for that matter) is apparently due to significant inertial effects acting from the vibration of the superstructure on the response of the pile head. These inertial effects cause relatively large curvatures in the pile in a localised region just below the pile cap and are more pronounced for relatively flexible piles.

Figure 4 illustrates the mean relationship between pile-head displacement and pile curvature for all six scenarios (i.e. the regression lines in Figure 3). Firstly, it is evident that the relationships for the relatively flexible $0.4 \mathrm{~m}$ diameter pile shown in Figure $4 \mathrm{a}$ all lie above the respective relationships for the relatively stiff $1.2 \mathrm{~m}$ diameter pile shown in Figure $4 \mathrm{~b}$. In other words, for a given level of pile-head displacement, $U_{p h}$, the peak curvature, $\phi_{p}$, of the flexible pile is, on average, larger than that for the stiffer pile. The ratio of curvatures for a given displacement is approximately eight for large curvatures, and approximately five for small (essentially elastic) curvatures Assuming that: (i) the plastic hinge length is proportional to the pile diameter; (ii) the effective length of the pile is constant; and (iii) that the pile cap provides zero rotation at the pile head, it can be deduced that for a given displacement at the pile head, the inelastic curvature for the $0.4 \mathrm{~m}$ diameter pile will be three times that of the $1.2 \mathrm{~m}$ diameter pile. However for the soil-pile model considered in this study, for a given pile-head displacement the curvature in the stiff pile will be further reduced 
(compared to the flexible pile) by the fact that the effective pile length will be longer for the stiff pile, and also because the larger relative stiffness between the pile and pile cap (compared to the flexible pile) will result in a larger rotation of the pile cap. Figure 4 also shows that the soil stiffness (within the range of values examined in this study) appears to have little effect on the relationship between pile-head displacement and pile curvature, as evident from the results for scenarios S1, S2 (1.2m diameter pile with $N^{(1)}=10$ and 20, respectively) and S3, S4 (0.4m diameter pile with $N^{(1)}=10$ and 20, respectively). The relative insensitivity of the pile response on the soil SPT blowcount can be explained by the fact that when changing the SPT blowcount from 10 to 20 the relative stiffness only changes by approximately $20 \%$ [22]. In contrast, when using the properties of the piles given in Table 1 , it can be shown that the difference in the relative stiffness between the pile and soil for the two different piles is a factor of about 2.3. Finally, the large deviation of the results for scenarios 5 and 6 illustrates the significant effect of the inertial load from the vibration of the superstructure on the pile response.

Clearly, a unique relationship between pile curvature (which relates directly to pile damage) and pile-head displacement does not exist, but rather this relationship is a function of the relative stiffness of the pile and the soil, and the presence of inertial loads at the pile head. As illustrated in Figure 3, for a single scenario however, there exists a relatively strong correlation between the pile-head displacement, $U_{p h}$, and pile curvature, $\phi_{p}$. As a result of this high correlation between peak pile curvature and peak pile-head displacement for a single scenario, those IMs which efficiently predict the peak pile-head displacement (as discussed in the next section) should also be efficient in predicting the peak pile curvature. This was found to be valid for all of the intensity measures investigated in the following sections. Thus for brevity, discussion herein on the pile response is given in terms of (peak) pile-head displacement only, but readers should interpret the results as also applying to peak pile 
curvature.

\section{INTENSITY MEASURES FOR NON-LIQUEFIABLE SOILS}

\section{Efficiency}

Figure $5 \mathrm{a}$ and $5 \mathrm{~b}$ illustrate the observed pile-head displacements from the 400 analyses in $\mathrm{S} 1$ for two intensity measures, $P G D$ and velocity spectrum intensity (VSI), respectively. The plots indicate the efficiency of these IMs. It is apparent that there is a significantly reduced scatter in the relationship between $U_{p h}$ and $\operatorname{VSI}(\beta=0.25)$ as compared to that of $U_{p h}$ and $P G D(\beta=0.54)$. If a $90 \%$ confidence interval (CI) [23] is constructed for the median level of demand for a given level of intensity, the ratio between the $5 \%$ and $95 \%$ values is 5.9 for $\mathrm{IM}=P G D$, and 2.3 for $\mathrm{IM}=V S I$ (i.e. the $95 \%$ value is 2.3 times the $5 \%$ value). Hence, the reduced dispersion gives a significantly reduced CI for the median demand. Obviously, in addition to this reduced CI for the median, a small dispersion means a smaller probability of very large demands for a given intensity, which affects the demand hazard [10].

Figure 6 summarises the dispersion values in the prediction of the pile-head displacements for the 19 examined IMs for scenarios S1-S4 in non-liquefiable soils. There are several key points to note in Figure 6. With the exception of $P G V$ for $\mathrm{S} 1$ and $\mathrm{S} 2$, the peak response values (i.e. $P G A, P G V, P G D$ ) tend to poorly correlate with the pile-head displacement. Similar trends are observed with the root-mean-square (RMS) IMs. In Figure 6, the difference (in dispersion values) between S1 and S2, and S3 and S4 for the same IM is relatively insignificant. This suggests that changing the SPT blow count of the soil from $N=10$ to $N=20$ (i.e. for $\mathrm{S} 1$ and $\mathrm{S} 3, N=10$; while $\mathrm{S} 2$ and $\mathrm{S} 4$ have $N=20$ ) does not affect the efficiency of various IMs (recall that the soil stiffness made little difference in the relationship between pile-head displacement and pile curvature also). This is not the case for liquefiable soils as discussed later in the manuscript. 
The effect of the superstructure properties on the efficiency of the various IMs is however quite significant. Recall that S1 and S2 have a 1.8s period superstructure, while S3 and S4 have a $0.8 \mathrm{~s}$ superstructure. This effect on IM efficiency is particularly pronounced for peak IMs such as $P G A$ and $P G V$, where it can be seen using $P G A$ is efficient for $\mathrm{S} 3$ and $\mathrm{S} 4$ (relative to $\mathrm{S} 1$ and $\mathrm{S} 2$ ), while $P G V$ is significantly more efficient for $\mathrm{S} 1$ and $\mathrm{S} 2$ (relative to $\mathrm{S} 3$ and S4). In fact, all the velocity-based IMs ( $\left.P G V, R M S_{v}, C A V, V S I, S M V\right)$ are observed to efficiently predict the pile-head displacement when the superstructure period is 1.8 seconds, as compared to the 0.8 second superstructure. The converse is true for all the accelerationbased IMs $\left(P G A, R M S_{a}, A S I, S M A, S_{a}(T=0.4,0.6,0.8 \mathrm{~s})\right)$, except of course $S_{a}(T=1.8 \mathrm{~s})$. These observations are in line with those of Riddell [19], who noted that the seismic response of stiff systems (with a low period of vibration) are efficiently predicted by acceleration-based IMs, while more flexible systems (in the constant velocity region of the response spectra) are better predicted by velocity-based IMs.

All four spectral acceleration IMs used were moderately efficient in predicting the pilehead displacements. For S3 and S4 (when the superstructure period was 0.8s), and for S1 and $\mathrm{S} 2$ (when the superstructure period was $1.8 \mathrm{~s}) S_{a}(T=0.8 \mathrm{~s})$ and $S_{a}(T=1.8 \mathrm{~s})$, respectively, result in dispersions in the range of $0.36-0.44$. The fact that the pile response is dependent on both kinematic and inertial mechanisms from the ground displacements and superstructure acceleration, respectively, is a likely reason that using the IMs at the vibration period of the superstructure (thus specifically targeting the inertial effects) does not result in a highly efficient IM. $\quad S_{a}(T=0.4 \mathrm{~s}), S_{a}(T=0.6 \mathrm{~s})$ and $S_{a}(T=0.8 \mathrm{~s})$ were used as a proxy for the kinematically induced response of the pile. The moderate performance of these spectral terms (which have dispersions of $0.35-0.5$ ) can be attributed to the fact that unlike structural systems (which exhibit a stable initial vibration period until significant inelastic action occurs due to yielding), no such initial period of soil exists during strong ground motion with inelastic 
behaviour occurring at low strain levels (e.g. Figure 2c).

In all four scenarios shown in Figure 6, VSI has the smallest dispersion. In other words, VSI has the best correlation with the pile response and provides the best prediction of the pilehead displacement. VSI (also referred to as Housner's intensity, SI, but referred to as VSI here to clearly distinguish between $A S I$ ) is defined as [24]:

$$
V S I=\int_{0.1}^{2.5} P S V(T, 5 \%) \mathrm{d} T
$$

where $\operatorname{PSV}(T, 5 \%)=$ the pseudo-velocity spectral ordinate for a period of vibration of $T$ and 5\% viscous damping. It can be seen from Equation (1) that unlike $S a$, VSI uses information about the properties of the ground motion record at multiple vibration frequencies, which appears to be significant in quantifying the complex and highly nonlinear soil-pile-structure response.

\section{Sufficiency}

IM sufficiency is important in addition to efficiency in seismic response analyses. As seismic response estimation is based on the response to a finite number of ground motion records, then the distribution of earthquake parameters (e.g. source distance, magnitude) of the selected ensemble of ground motion records may not strictly represent the distribution of ground motions which may occur at the site in the future. It is therefore desirable that the results of the response analyses are practically independent (over a reasonable range) of these earthquake characteristics. If independence is not satisfied then multiple integration would be required over all significant earthquake parameters, significantly complicating the use of the

IM. A typical example of an IM not being independent of other earthquake parameters, is the dependence of liquefaction development on both $P G A$ and moment magnitude, $M_{w}[10]$.

In order to investigate the additional information that ground motion parameters provide for responses which are already conditioned on the primary IM (e.g. VSI), the dependence of 
the residuals of the responses on other ground motion parameters is investigated. The residual is the arithmetic difference between an individual data point, $\left(\mathrm{IM}_{i}, \mathrm{EDP}_{i}\right)$, and the predicted EDP value from the regression, $\left(I M_{i}, \overline{E D P}\right)$. By taking the residual of the responses conditioned on the primary IM, the influence of this IM is removed. Thus, if a significant dependence is found between the residuals and some other ground motion parameter, it indicates that this ground motion parameter should also be considered when conducting the seismic response analyses. Using an F-test [23], a so-called p-value is used as a quantitative measure of this independence, which gives, in this case, the probability that the (absolute) slope of the trend line through the residuals is at least as large as that observed (and therefore that the EDP prediction based on IM is independent of the considered ground motion parameter). Although somewhat subjective, generally a p-value of less than 0.05 indicates that there is evidence that the slope is non-zero, and a p-value less than 0.01 indicates strong evidence.

Figures 7a-7f illustrate the sufficiency of $P G A$-, $P G V$-, and $V S I$-based pile displacement responses with respect to earthquake moment magnitude $\left(M_{w}\right)$ and source distance $(R)$ for the S1 analyses. Note that when conducting conventional PSHA, integration is performed over three parameters, $M_{w}, R$, and $\varepsilon$ (epsilon), hence the reason why the sufficiency with respect to these parameters is important. It can be seen that the $P G V$-based response is less dependent on both magnitude and source distance than the $P G A$-based response. Nevertheless, the pvalues in Figure 7a-7d are notably low (only the dependence on distance of $P G V$-based responses is above 0.05). It appears somewhat surprising that the sufficiency of $P G V$-based responses is poor considering that the efficiency of $P G V$ for the $\mathrm{S} 1$ analyses was very good. It should be noted however that the dependence on magnitude should be interpreted with some caution due to the relatively small variation in the magnitude values of the 40 ground motion records used here. Figure $7 \mathrm{e}$ and $7 \mathrm{f}$ illustrate the sufficiency of the VSI-based pile responses 
with respect to $M_{w}$ and $R$, respectively. The sufficiency exhibited is significantly superior to that of $P G V$ and $P G A$ for both $M_{w}$ and $R$, and the p-values of 0.54 and 0.56 , respectively, illustrate that practically there is no dependence on $M_{w}$ or $R$ when scaling records for pile response based on VSI.

Epsilon, $\varepsilon$, is defined as the number of standard deviations $\mathrm{IM}=\mathrm{im}$ is from the median value, $\overline{I M}$, predicted from a ground motion prediction relationship. Epsilon is important in structural analyses as it has been shown that it is a proxy of the spectral shape in the frequency region of the IM, which is usually set equal to the fundamental period of the structure, $S_{a}\left(T_{1}\right)$ $[17,18]$. The spectral shape will have a direct effect on the level of excitation which will occur due to higher-mode effects and effective period lengthening due to nonlinear behaviour. As VSI is dependent on the spectral velocity over a range of periods, then it directly accounts for the shape of the spectra (over this range of periods), and thus it seems logical that the dependence of VSI on epsilon is somewhat less compared to its effect when using $S_{a}\left(T_{l}\right)$. Figure 8 illustrates the sufficiency of VSI with respect to epsilon for S1. Although there appears to be a slight negative trend in the residuals as a function of epsilon, the p-value of 0.03 indicates that this dependence is relatively insignificant. Similar results for the sufficiency of VSI with respect to epsilon were observed for the other scenarios investigated in this study.

\section{Distribution of demand for a given intensity}

When considering the relationship between seismic demand and ground motion intensity (EDP|IM) within the PBEE framework, knowledge of the distribution of EDP|IM is required. While several investigations in structural earthquake engineering indicate that the lognormal distribution can accurately represent the distribution of $\operatorname{EDP} \mid \operatorname{IM}$ (e.g. $[25,26])$, the highly nonlinear soil-pile-structure interaction and potential occurrence of liquefaction in strong ground motion shaking may mean that the seismic demand on the piles and soil 
response in general does not follow this common analytical distribution.

Figure 9 illustrates the validity of the lognormal assumption for a variety of seismic intensity measures, scenarios and intensity levels. Namely, EDPs considered were peak freefield soil displacement $\left(U_{g}\right)$, peak pile-head displacement $\left(U_{p h}\right)$, and peak pile curvature $\left(\phi_{p}\right)$ based on IMs: $P G A, P G V$ and VSI. Figure 9 illustrates that various combinations of these EDPs and IMs all can be assumed to have a lognormal distribution for EDP|IM based on the Kolmogorov-Smirnov (K-S) goodness-of-fit test at a 10\% confidence level [23]. From the above observations (as well as additional analyses not discussed herein) it would seem logical that the seismic demand will also be well approximated by the lognormal distribution for piles in liquefiable and non-liquefiable soils.

\section{Predictability}

When selecting an IM suitable for seismic response analysis, consideration must also be given to the predictability of the IM which influences the ground motion hazard curve determined via PSHA. Kramer and Mitchell [10] illustrate how significant uncertainty in the ground motion prediction model for the IM will cause an increase in the ground motion hazard, and in turn an increase in the demand hazard. In other words, if the predictability of an IM is poor, then the accuracy in predicting the pile response (for a given earthquake scenario, $\left.M_{w}, R\right)$ will also be poor. In this context, it is important to examine the predictability of VSI, which from the results of the analyses presented so far, is undoubtedly the optimal IM for pile response in terms of efficiency and sufficiency.

Unlike $P G A$, for example, there are few ground motion prediction equations for directly predicting VSI. Here, the VSI prediction equation presented in Danciu and Tselentis [27] will be used. Although beyond the scope of this study, it is noted that it is possible to obtain a ground motion prediction equation for VSI from spectral acceleration prediction relationships [28], thus allowing VSI to be computed at all sites where applicable spectral acceleration 
relationships are available.

Comparison of the various ground motion prediction equations of Danciu and Tselentis [27] illustrates that VSI is also an IM with good predictability; the prediction equation for VSI has a dispersion of 0.73 compared to that of $P G A$ and $P G V$ which have dispersions of 0.67 and 0.71 , respectively (in terms of the natural logarithm, lnIM, and not the base 10 logarithm, $\left.\log _{10} \mathrm{IM}\right)$.

By combining the ground motion hazard with the seismic response analyses, the demand hazard can be obtained from:

$$
\lambda_{E D P}(e d p)=\int G_{E D P \mid M}(e d p \mid i m)\left|\frac{d \lambda_{I M}(i m)}{d I M}\right| \operatorname{dim}
$$

where $G_{E D P \mid I M}(e d p \mid i m)$ is the complementary cumulative distribution function for EDP|IM, which gives the probability of exceeding $\mathrm{EDP}=e d p$ given $\mathrm{IM}=i m$; and $\lambda_{Z}(z)$ gives the annual rate of exceeding $Z=z$. In this case, Equation (2) gives the annual frequency of exceeding various levels of peak pile-head displacement. Figure 10 illustrates the demand hazard curves obtained for S3 using VSI and $P G V$ as IMs. For consistency regarding site classification factors and faulting style, the ground motion attenuation models of Danciu and Tselentis [27] were used for both $V S I$ and $P G V$. In producing the demand hazard curves shown in Figure 10, a hypothetical site on stiff soil is considered (as used in [10]) which is $R=30 \mathrm{~km}$ from a single strike-slip fault point source, with a magnitude recurrence relationship given by $\log _{10} \lambda_{M_{w}}=4.0-0.8 M_{w}$. The dispersions in the seismic response analyses for $V S I$ and $P G V$ were 0.305 and 0.395 , respectively. It is evident that the difference in dispersion is the key contributor to the difference in the hazard curves, since the attenuation relationships of both $V S I$ and $P G V$ have similar dispersions of 0.73 and 0.71 , respectively [27].

Figure 10a illustrates that using the $V S I$ - and $P G V$-based scaling of the ground motion records gives pile-head displacements of approximately $0.18 \mathrm{~m}$ and $0.215 \mathrm{~m}$, respectively for 
the $10 \%$ in 50 year exceedance frequency. At the $2 \%$ in 50 year exceedance frequency VSIand $P G V$-based demands are $0.41 \mathrm{~m}$ and $0.48 \mathrm{~m}$, respectively. In other words, using $P G V$ will over predict the seismic demand on the pile (for a given exceedance rate) by approximately $20 \%$ compared to using VSI. Investigation of Figure 10a in terms of rate of exceedance for a given level of demand indicates that for a pile-head displacement of $0.2 \mathrm{~m}$ the rates of exceedance are $2.3 \times 10^{-3}$ and $1.8 \times 10^{-3}$ using $P G V$ and $V S I$, respectively. At a pile-head displacement of $0.5 \mathrm{~m}$ the rates of exceedance are $3.2 \times 10^{-4}$ and $2.3 \times 10^{-4}$ using $P G V$ and $V S I$, respectively. Thus at pile-head displacements of 0.2 and $0.5 \mathrm{~m}$ using VSI gives a reduction in the rate of exceedance by $27 \%$ and $37 \%$, respectively compared to using $P G V$. Figure $10 \mathrm{~b}$ illustrates the hazard curves for the peak pile curvature and hence damage to the pile using the same two ground motion IMs as above. Superimposed on the figure is the pile curvature levels at which the pile is deemed to exceed yield and ultimate limit states. Thus, it has been assumed that the limit states are a binary function of the demand (in reality the limit states will have some distribution due to cyclic loading effects, material randomness, axial load etc.). For the yielding limit state the annual frequencies of exceedance are $0.025,0.028$ for VSI-, and $P G V$-based scaling, respectively. That is, for this hypothetical high seismic region the return period for pile yielding ranges from 36 to 40 years depending on the IM used. For the ultimate limit state the effects of uncertainty are more pronounced with frequencies of $3.5 \times 10^{-4}$ and $4.5 \times 10^{-4}$ for the VSI- and $P G V$-based scaling, respectively. Thus the return periods for pile failure range from approximately 2200 to 2860 years (a $30 \%$ difference). As previously mentioned, the strong correlation between pile curvature and pile-head displacement illustrates that VSI is an efficient predictor of both the pile-head displacement and the pile curvature or damage to the pile. 


\section{INTENSITY MEASURES FOR LIQUEFIABLE SOILS}

Thus far the performance of the various intensity measures has been presented with respect to the seismic response analysis for the case of non-liquefiable soils. Seismic response analyses using the same six scenarios presented in Figure $2 b$ were also conducted where the effects of excess pore water pressures and eventual liquefaction were explicitly modelled.

As many of the previous comments made regarding IMs for the non-liquefiable soil scenarios are also applicable to the scenarios using liquefiable soils, then attention here is primarily limited to the discussion of the efficiency of the various IMs. Comparison of the relationship between peak pile curvature and peak pile-head displacement from the analyses with liquefiable soils revealed similar trends as that in non-liquefiable soils and therefore peak pile-head displacement was again used as the EDP.

\section{Efficiency of IMs for predicting $\boldsymbol{U}_{p h}$ in liquefiable soils}

Figure 11 illustrates the dispersion in the prediction of the (maximum) pile-head displacements as a function of the various IMs for the first four scenarios listed in Figure $2 b$, for simulations with liquefiable soils. Note that several dispersion results were above 0.8 (notably the significant duration, $\mathrm{D}_{\mathrm{s}}$ ) and are thus not shown in the plot. The variation in the dispersion for a single IM over the four different scenarios illustrates that the specific model configuration does have an effect on the efficiency of the IM. In particular, the effect of the SPT blow count for the top soil layer (either $N^{(1)}=10$ or 20) appears to be significant for the efficiency of some IMs. This result is distinctly different from that of piles embedded in nonliquefiable soils (Figure 6). As was observed in Figure 6, Figure 11 shows that pile-head displacements in liquefiable soils are most efficiently predicted (i.e. show smallest uncertainty) using velocity-based IMs, such as $P G V, R M S_{v}, V S I$, and $S M V$. Peak ground acceleration, $P G A$, and peak ground displacement, $P G D$, provide poor prediction of the response over all four scenarios. Arias Intensity, $I_{a}$, which is a measure often used in 
liquefaction evaluation [29] was found to correlate poorly with pile-head displacement, with dispersions above 0.35 for all four scenarios. Spectral acceleration quantities (IM numbers 16-20) tend to predict the pile response in S2 and S4 (where the top layer of soil has $N^{(1)}=20$ ) with moderate efficiency (dispersions of approximately 0.35 ), but their prediction for S1 and S3 (where the top layer of soil has $N^{(1)}=10$ ) is very poor. This is due to the larger nonlinearity and liquefaction observed in the analyses with the $N^{(l)}=10$ soil layer compared to the $N^{(1)}=20$ layer.

Figure 11 illustrates that VSI is the most efficient IM for predicting the seismic response of piles embedded in liquefiable soils, which was also the most efficient IM for pile response in non-liquefiable soils (Figure 6). To illustrate this further, Table 3 compares the efficiency of VSI in predicting pile-head displacements for all six scenarios, for liquefiable and nonliquefiable soil. Three features are apparent upon inspection of Table 3: (i) prediction of pilehead displacement in liquefying soils is less uncertain than in non-liquefying soils; (ii) VSI is more efficient at predicting peak pile response when the period of the superstructure is $T=1.8 \mathrm{~s}$ (S1 vs S3; S2 vs S4); and (iii) prediction of the pile response when inertial effects are absent (i.e. S5 and S6) is not noticeably improved as compared to the case when both kinematic and inertial effects are present. With respect to the first point, it is important to recall that the analyses with liquefiable soils were conducted up to $0.5 \mathrm{~g} P G A$, while those for nonliquefiable soils were conducted up to $1.0 \mathrm{~g} P G A$.

\section{EFFECTS OF SOIL-PILE INTERACTION ON EFFICIENCY}

\section{Prediction of ground displacement for liquefiable and non-liquefiable soils}

Figure 12a illustrates the efficiency of various IMs in predicting the maximum free-field ground displacement, $U_{g}$, for the two different soil profiles considered in this study, with a top layer of $N^{(1)}=10$ or $N^{(1)}=20$, respectively. Over all of the different IMs considered in the 
analyses, the free-field soil response is predicted more efficiently for the soil profile having a top layer of $N^{(1)}=20$ than for a top layer of $N^{(1)}=10$. This observation is different from the prediction of free-field displacements for non-liquefiable soils shown in Figure 12b, where the efficiency is practically independent of the stress-strain characteristics of the soil. This result is due to the pronounced effects of liquefaction on the stress-strain response of the soil with $N^{(1)}=10$ relative to that with $N^{(l)}=20$ blow counts. Note that even though liquefaction was induced in the analyses with the $N^{(1)}=20$ top soil layer, the peak shear strains were significantly less than those developed in the models within the $N^{(1)}=10$ top soil layer. The reason for the slightly smaller dispersions in free-field soil response for liquefiable soils with $N^{(1)}=20$ compared to those of non-liquefiable soils, is due to the smaller range of ground motion intensity used in the liquefaction analyses (0.05-0.5g $P G A$ and $0.1-1.0 \mathrm{~g} P G A$ for liquefiable and non-liquefiable analyses, respectively).

\section{Efficiency of predicting pile-head displacement: effect of relative pile stiffness}

Figure 13 illustrates the relationship between peak pile-head displacement and peak free-field displacement for all of the analyses used in S5 and S6, i.e. those without inertial effects from the superstructure. Figures 13a and 13b illustrate that during small ground shaking the magnitude of the free-field and pile-head displacements are similar for both the $1.2 \mathrm{~m}(\mathrm{~S} 5)$ and $0.4 \mathrm{~m}(\mathrm{~S} 6)$ diameter pile. However, as the free-field ground displacements increase (due to an increase in the level of ground motion intensity), significant liquefaction occurs in the upper layer of the soil deposit, and the $1.2 \mathrm{~m}$ diameter pile exhibits a relatively stiff behaviour, with pile displacements significantly less that that of the free-field soil (i.e. the pile is stiff enough to resist the ground movement). Figure $13 \mathrm{~b}$ illustrates, however, that for the $0.4 \mathrm{~m}$ diameter pile the relationship between pile-head displacement and free-field displacement is almost one-to-one for all ranges of ground motion intensity, and the pile even 'over-shoots' the ground displacement at large intensity levels. This response is typical for a 
relatively flexible pile in which the pile generally follows the ground movement.

Figure 14 illustrates the efficiency in predicting the pile-head displacements for S5 and S6 as well as the efficiency in the prediction of the maximum free-field ground displacements. Recall that both S5 and S6 have a top soil layer of $N^{(1)}=10$ and no superstructure, with the only difference being the diameter of the pile ( $\mathrm{S} 5$ has $\mathrm{D}_{0}=1.2 \mathrm{~m}$ and $\mathrm{S} 6$ has $\mathrm{D}_{0}=0.4 \mathrm{~m}$ ). Thus, Figure 14 allows direct consideration of the effects of the relative pile stiffness on the efficiency of the different IMs, without influence of the superstructure. Several features of Figure 14 are worthy of note: (i) over the entire range of the examined IMs the efficiency in predicting pile-head displacements and free-field ground displacements for the pile with $D_{o}=0.4 \mathrm{~m}(\mathrm{~S} 6)$ is almost identical, indicating that this pile exhibited a flexible-pile behaviour and moved together with the free-field soil; (ii) the efficiency of predicting the pile-head displacements for the stiffer pile with $D_{o}=1.2 \mathrm{~m}(\mathrm{~S} 5)$ is greater than that for S6 across all of the IMs considered here; and (iii) velocity-based IMs (namely $V S I$ and $P G V$ ) were the most efficient in predicting the free-field ground displacements and thus the imposed kinematic loads on the pile foundation. It is worth noting that the removal of the inertial effects, on average, did not improve the efficiency of the IMs at predicting the peak pile-head displacement, as evident from a comparison of Figure 14 with S1 and S2 in Figure 11.

\section{CONCLUSIONS}

Ground motion intensity measures (IM's) for the evaluation of the seismic performance of pile foundations within the Pacific Earthquake Engineering Research (PEER) Centre framework has been investigated in this study. The seismic response of pile foundations during strong ground motion is complex and depends on both kinematic effects from the imposed soil displacements and inertial effects from the vibration of the superstructure. A simplified model of a soil-pile-structure system was considered in this study to capture the 
salient features of the pile response during ground motion excitation. Forty ground motion records were scaled to peak accelerations ranging from $0.1 \mathrm{~g}$ to $1.0 \mathrm{~g}$ resulting in 400 seismic analyses for a given scenario. Various soil-pile-structure scenarios were considered allowing for the effects of various soil, pile and superstructure characteristics on the dynamic response of the system. In total, twelve different scenarios were considered; six for piles in nonliquefiable soils and six for piles in liquefiable soils. It was observed that the peak lateral pile-head displacement correlated well with the peak curvature of the pile, particularly when kinematic effects dominate the response of the pile foundation. Hence, the peak pile-head displacement can be used as an EDP for piles and is an approximate measure for the damage to the pile. The relationship between the peak pile-head displacement and the peak pile curvature is not unique, but rather it is a function of the properties of the soil-pile-structure system.

Over all twelve scenarios considered it was found that velocity spectrum intensity (VSI) (also known as Housner spectrum intensity, $S I$ ) predicted the peak pile-head displacement with the lowest uncertainty (highest efficiency). This was primarily due to the capability of VSI in predicting peak free-field soil displacements which cause kinematic-induced loads on the pile foundation. In addition to having the highest efficiency in the response prediction, VSI was found to be sufficient with respect to magnitude, source distance and epsilon, both in absolute terms, and relative to the performance of other IMs, e.g. peak ground acceleration and peak ground velocity. VSI was also found to be a predictable intensity measure, and it was illustrated how its use can reduce the peak pile-head displacement demand hazard compared to other measures of ground motion intensity. The above conclusions apply both to piles in non-liquefiable and liquefiable soils.

The effects of the deformation mechanism of the soil-pile system were also found to be significant with the pile response being more efficiently predicted when stiff-pile behaviour, 
as opposed to flexible-pile behaviour was exhibited for pile response in liquefiable soils.

Despite being based on single-pile models, this study provides clear indications of the efficacy of various IMs in predicting the seismic response of pile foundation within the PBEE framework. Further studies are underway to quantify the effectiveness of the proposed EDPs and IMs for pile groups and capture specific cross-interaction effects on the response of the soil-pile-structure system.

\section{ACKNOWLEDGEMENTS}

Financial support of the first author by the New Zealand Tertiary Education Commission is greatly appreciated. 


\section{REFERENCES:}

[1] Tokimatsu K, Mizuno H, Kakurai M, Building damage associated with geotechnical problems, Soils and foundations, Special Issue on Geotechnical Aspects of the January 171995 Hyogoken-Nambu Earthquake, No. 1, 1996:219-234.

[2] Gazetas G, and Mylonakis G, Seismic soil-structure interaction: new evidence and emerging issues, in Geotechnical Earthquake Engineering and Soil Dynamics III (GSP 72,2), 1998 p. 1119-1174

[3] Tokimatsu K, and Asaka Y, Effects of liquefaction-induced ground displacements on pile performance in the 1995 Hyogoken-Nambu Earthquake, Soils and Foundations, Special Issue, 1998:163-177.

[4] Ishihara K, and Cubrinovski M, Case studies of pile foundations undergoing lateral spreading in liquefied deposits, state-of-the-art paper, in 5th International Conference on Case Histories in Geotechnical Engineering, New York, 2004

[5] Cornell CA, and Krawinkler H, Progress and challenges in seismic performance assessment, PEER Center News, 2000;3(2).

[6] Deierlein GG, Krawinkler H, Cornell CA, A framework for performance-based earthquake engineering, in Pacific Conference on Earthquake Engineering, Christchurch, New Zealand, 2003

[7] Mehanny SSF, and Ayoub AS, Variability in inelastic displacement demands: uncertainty in system parameters versus randomness in ground records, Engineering Structures, 2008;30:1002-1013.

[8] Shome N, and Cornell CA, Probabilistic seismic demand analysis of nonlinear structures, Stanford University, Stanford, CA Report No. RMS-35, RMS Program, $1999,357$.

[9] Luco N, and Cornell CA, Structure-specific scalar intensity measures for near-source and ordinary earthquake ground motions, Earthquake Spectra, 2007;23(2):357-392.

[10] Kramer SL, and Mitchell RA, Ground motion intensity measures for liquefaction hazard evaluation, Earthquake Spectra, 2006;22(2):413-438.

[11] Diana-J3, Finite-element program for effective stress analysis of two-phase soil medium, 1997,

[12] Cubrinovski M, and Ishihara K, Modelling of Sand Behaviour based on state concept, Soils and Foundations, 1998;28(3):115-127.

[13] Cubrinovski M, and Ishihara K, State Concept and Modified Elastoplasticity for Sand Modelling, Soils and foundations, 1998;38(4):213-225.

[14] Cubrinovski M, Uzuoka R, Sugita H, Tokimatsu K, Sato M, Ishihara K, et al., 
Prediction of pile response to lateral spreading by 3-D soil-water coupled dynamic analysis: shaking in the direction of ground flow, Soil Dyn. Earthquake Eng., 2008;28(6):421-435.

[15] Seed RB, and Idriss IM, Soil moduli and damping factors for dynamic response analysis, Earthquake Engineering Research Center, UC Berkeley, CA 1970, 48.

[16] Medina RA, and Krawinkler H, Seismic demands for nondeteriorating frame structures and their dependence on ground motions, John A. Blume Earthquake Engineering Center, Stanford University, Stanford, CA. 2003, 373 pp.

[17] Tothong P, and Luco N, Probabilistic Seismic Demand Analysis Using Advanced Ground Motion Intensity Measures, Earthquake Eng. Struct. Dyn., 2007;36(13):18371860 .

[18] Baker JW, and Cornell CA, A vector-valued ground motion intensity measure consisting of spectral acceleration and eplison, Earthquake Eng. Struct. Dyn., 2005;34(10):1193-1217.

[19] Riddell R, On ground motion intensity measures, Earthquake Spectra, 2007;23(1):147-173.

[20] Park YJ, and Ang AHS, Mechanistic Seismic Damage Model for Reinforced Concrete, Journal of Structural Division, ASCE, 1985;111(4):722-739.

[21] Porter K, Kennedy R, Bachman R, Creating Fragility Functions for Performance-based Earthquake Engineering, Earthquake Spectra, 2007;23(2):471-489.

[22] Cubrinovski M, and Ishihara K, Simplified method for analysis of piles undergoing lateral spreading in liquefied soils, Soils and Foundations, 2004;44(25):119-133.

[23] Ang AHS, and Tang WH, Probability Concepts in Engineering Planning and Design vol. Volume I - Basic Principles: John Wiley \& Sons, Inc., 1975.

[24] Housner GW, Spectrum intensities of strong-motion earthquakes, in Symposium on earthquakes and blast effects on structures, Los Angeles, CA, 1952

[25] Aslani H, and Miranda E, Probability-based Seismic Response Analysis, Engineering Structures, 2005;27(8):1151-1163.

[26] Mander JB, Dhakal RP, Mashiko N, Solberg KM, Incremental dynamic analysis applied to seismic financial risk assessment of bridges, Engineering Structures, 2007;29(10):2662-2672.

[27] Danciu L, and Tselentis GA, Engineering Ground motion Attenuation Relationships for Greece, Bull. Seism. Soc. Am., 2007;97(1B):162-183.

[28] Bradley BA, Cubrinovski M, MacRae GA, Dhakal RP, Ground motion prediction equation for Spectum intensity from spectral acceleration relationships, Bull. Seism. Soc. Am. (in press), 2008.

[29] Kayen RE, and Mitchell JK, Assessment of liquefaction potential during earthquakes 
by Arias intensity, Journal of Geotechnical and Geoenvironmental Engineering, 1997;123(12):1162-1174. 
Table 1: Properties of pile foundations used in analysis

\begin{tabular}{|c|c|c|}
\hline & $\begin{array}{c}\mathrm{D}_{0}=0.4 \mathrm{~m} \\
\text { PC pile }\end{array}$ & $\begin{array}{c}\mathrm{D}_{0}=1.2 \mathrm{~m} \\
\text { RC pile }\end{array}$ \\
\hline $\begin{array}{c}\text { Initial Stiffness, EI } \\
\left(\mathrm{MN}-\mathrm{m}^{2}\right)\end{array}$ & 42.3 & 2340 \\
\hline $\begin{array}{c}\text { Ultimate Moment, } \mathrm{M}_{\mathrm{u}} \\
(\mathrm{MN}-\mathrm{m})\end{array}$ & 0.135 & 2.46 \\
\hline Axial Load, N, $(\mathrm{kN})$ & 400 & 2500 \\
\hline Reinforcement ratio, $\rho$ & $0.3 \%$ & $0.5 \%$ \\
\hline Prestress level $(\mathrm{MPa})$ & 4.0 & 0.0 \\
\hline $\begin{array}{c}\text { Steel yield stress, } f_{y} \\
(\mathrm{MPa})\end{array}$ & 1320 & 340 \\
\hline $\begin{array}{c}\text { Concrete crushing } \\
\text { strength, } f_{c}{ }^{\prime}(\mathrm{MPa})\end{array}$ & 50.0 & 25.0 \\
\hline
\end{tabular}

Table 2: Intensity Measures used in analyses

\begin{tabular}{|r|l|}
\hline \multicolumn{1}{|r|}{ ID } & Intensity Measure (IM) \\
\hline 1 & Peak ground acceleration, $P G A$ \\
\hline 2 & Peak ground velocity, $P G V$ \\
\hline 3 & Peak ground displacement, $P G D$ \\
\hline 4 & Significant duration, $\mathrm{D}$ \\
\hline 5 & $P G V / P G A, \mathrm{~V}_{\max } / \mathrm{A}_{\max }$ \\
\hline 6 & RMS acceleration, $\mathrm{RMS}_{\mathrm{a}}$ \\
\hline 7 & RMS velocity, $\mathrm{RMS}_{\mathrm{v}}$ \\
\hline 8 & RMS displacement, $\mathrm{RMS}_{\mathrm{d}}$ \\
\hline 9 & Arias intensity, $\mathrm{I}_{\mathrm{a}}$ \\
\hline 10 & Specific energy density, dE \\
\hline 11 & Cumulative absolute velocity, CAV \\
\hline 12 & Acceleration spectrum intensity, ASI \\
\hline 13 & Velocity spectrum intensity, $V S I$ \\
\hline 14 & Sustained maximum acceleration, SMA \\
\hline 15 & Sustained maximum velocity, SMV \\
\hline 16 & Spectral acceleration, $\mathrm{S}_{\mathrm{a}}(\mathrm{T}=0.4 \mathrm{~s}, 5 \%)$ \\
\hline 17 & Spectral acceleration, $\mathrm{S}_{\mathrm{a}}(\mathrm{T}=0.6 \mathrm{~s}, 5 \%)$ \\
\hline 18 & Spectral acceleration, $\mathrm{S}_{\mathrm{a}}(\mathrm{T}=0.8 \mathrm{~s}, 5 \%)$ \\
\hline 19 & Spectral acceleration, $\mathrm{S}_{\mathrm{a}}(\mathrm{T}=1.8 \mathrm{~s}, 5 \%)$ \\
\hline
\end{tabular}


Table 3: Efficiency of VSI in predicting peak pile head displacements

\begin{tabular}{|c|c|c|}
\hline \multirow{2}{*}{ Scenario } & \multicolumn{2}{|c|}{ Dispersion, $\beta_{\ln U_{p h} \mid V S I}$} \\
\cline { 2 - 3 } & Liquefiable soil & Non-liquefiable soil \\
\hline S1 & 0.233 & 0.255 \\
\hline S2 & 0.194 & 0.242 \\
\hline S3 & 0.261 & 0.304 \\
\hline S4 & 0.253 & 0.288 \\
\hline S5 & 0.252 & 0.29 \\
\hline S6 & 0.265 & 0.307 \\
\hline
\end{tabular}




$$
\begin{aligned}
& \left.\left.\left.\left.\left(\begin{array}{l}
\text { Ground } \\
\text { Motion } \\
\text { Hazard }
\end{array}\right) \mathrm{IM}\right\rangle\left(\begin{array}{c}
\text { Seismic } \\
\text { Response }
\end{array}\right) \operatorname{EDP}\right\rangle\left(\begin{array}{c}
\text { Damage to } \\
\text { Components }
\end{array}\right) \mathrm{DM}\right\rangle\left(\begin{array}{c}
\text { Repair Costs, } \\
\text { Casualties, } \\
\text { Downtime }
\end{array}\right) \mathrm{DV}\right\rangle \\
& \text { Intensity } \\
& \text { Engineering } \\
& \text { Damage }
\end{aligned}
$$

Figure 1: Schematic illustration of the key tasks in the PBEE methodology 

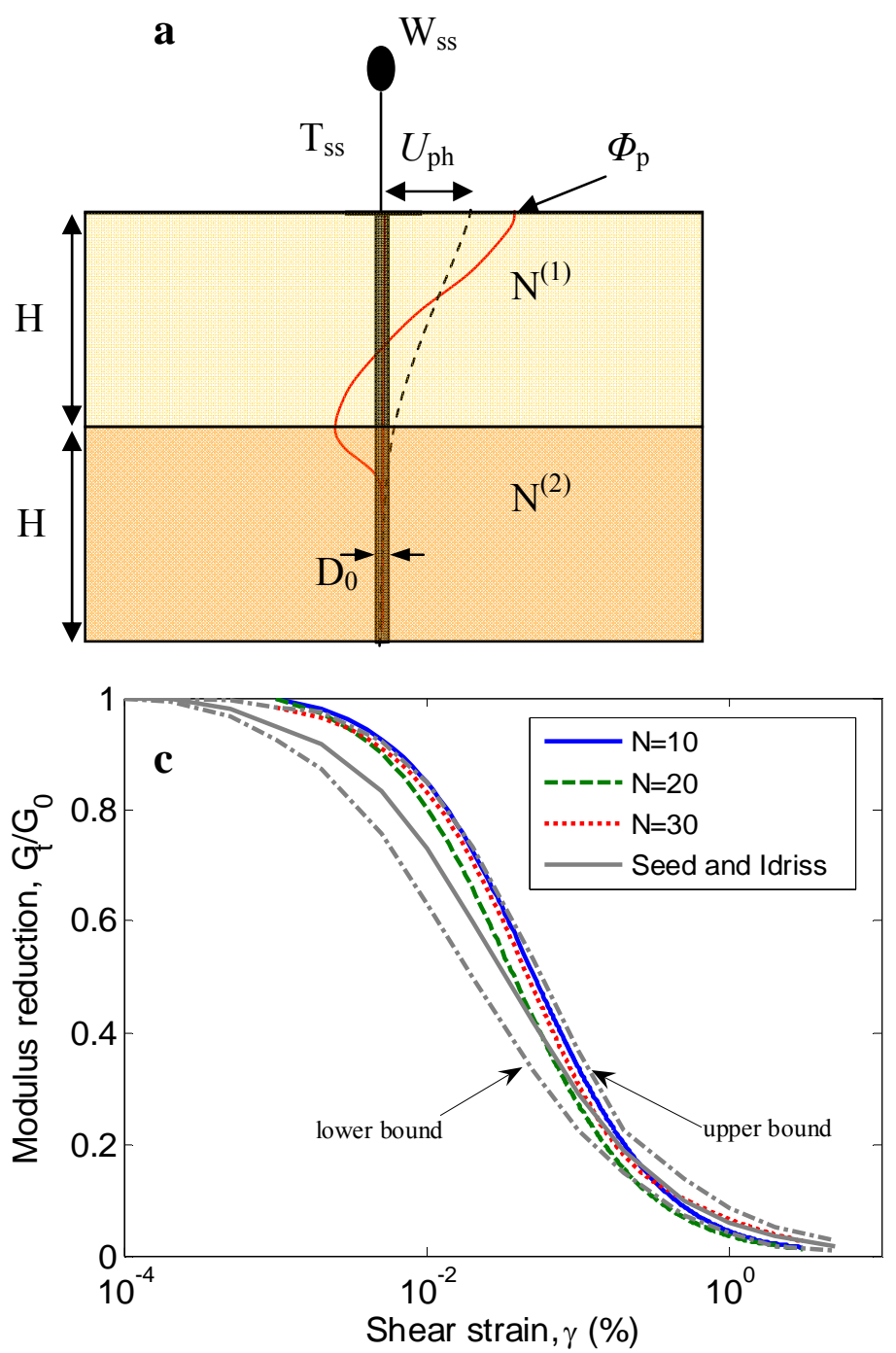

\begin{tabular}{|c|c|c|c|c|c|c|}
\hline Mgdel & \multicolumn{7}{|c|}{ Scenario } \\
\hline Parameter & $\mathbf{1}$ & $\mathbf{2}$ & $\mathbf{3}$ & $\mathbf{4}$ & $\mathbf{5}$ & $\mathbf{6}$ \\
\hline $\mathbf{N}^{(\mathbf{1})}$ & 10 & 20 & 10 & 20 & 10 & 10 \\
\hline $\mathbf{N}^{(\mathbf{2})}$ & 30 & 30 & 30 & 30 & 30 & 30 \\
\hline $\mathbf{W}_{\text {ss }}(\mathbf{k N )}$ & 2500 & 2500 & 400 & 400 & - & - \\
\hline $\mathbf{T}_{\text {ss }}(\mathbf{s})$ & 1.8 & 1.8 & 0.8 & 0.8 & - & - \\
\hline $\mathbf{D}_{\mathbf{0}} \mathbf{( c m )}$ & 120 & 120 & 40 & 40 & 120 & 40 \\
\hline $\mathbf{H} \mathbf{( m )}$ & 10 & 10 & 10 & 10 & 10 & 10 \\
\hline
\end{tabular}

$\mathrm{N}^{(i)}=$ SPT blow count of layer $i$

$\mathrm{W}_{\mathrm{ss}}=$ weight of superstructure

$\mathrm{T}_{\mathrm{ss}}=$ period of superstructure

$\mathrm{D}_{0}=$ diameter of pile

$\mathrm{H}=$ depth of soil layer

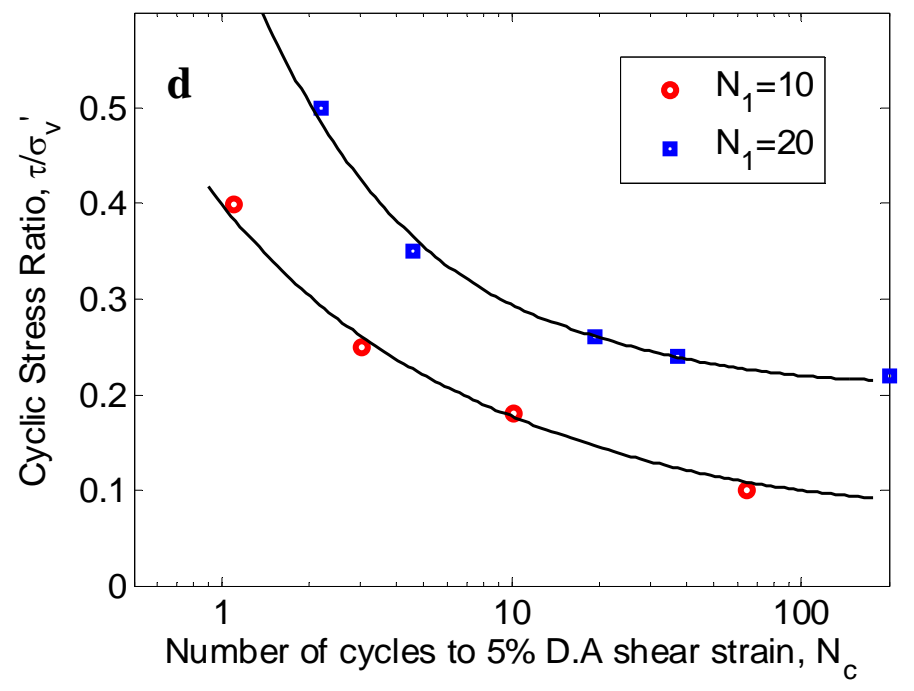

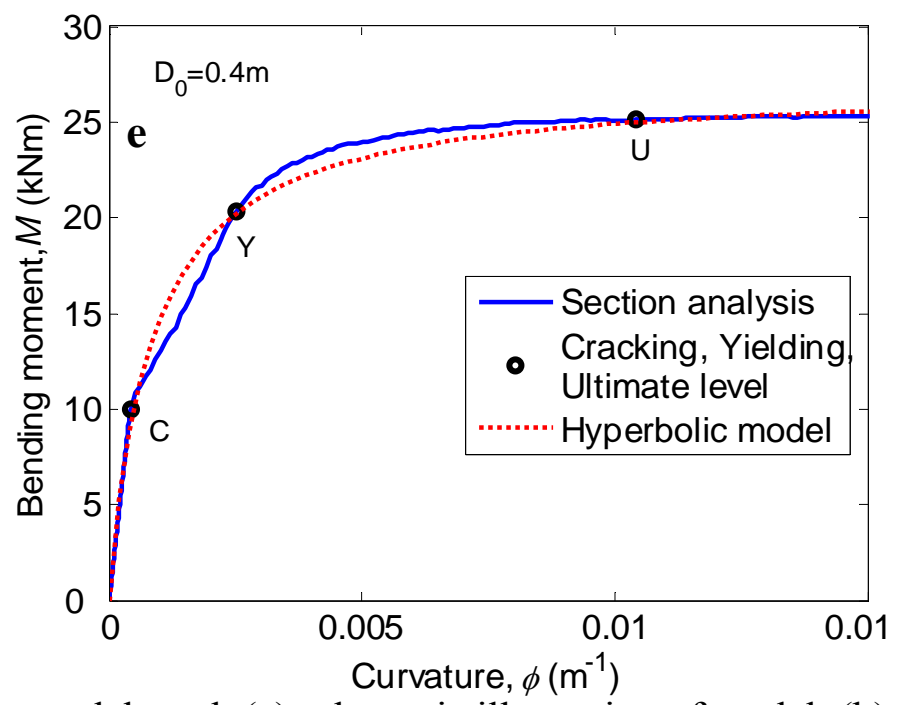

Figure 2: Soil-pile-structure model used: (a) schematic illustration of model; (b) scenarios considered; (c) modulus reduction curves; (d) liquefaction resistance curves; and (e) hyperbolic approximation of M- $\Phi$ relationship for the pile. 

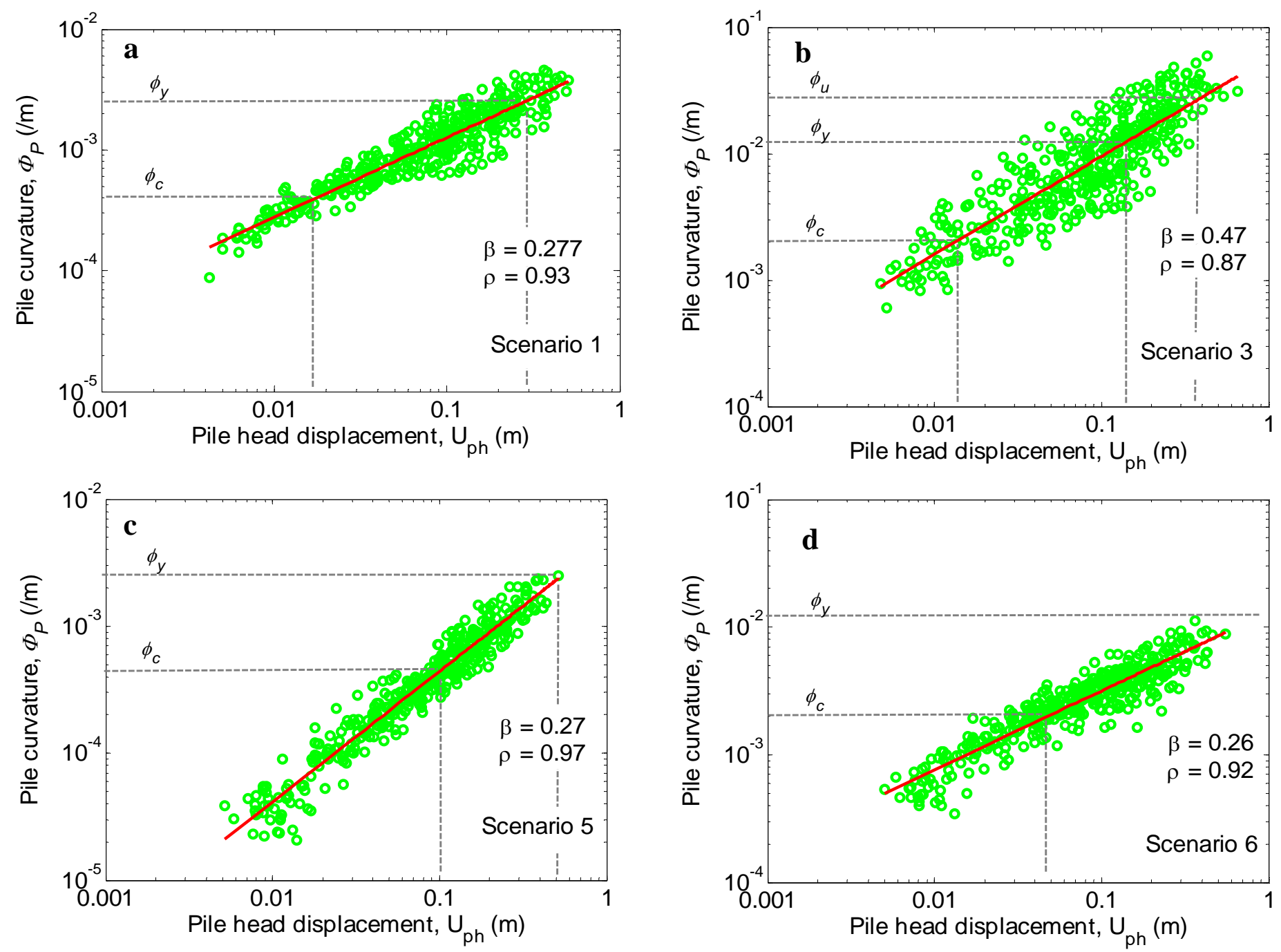

Figure 3: Correlation between peak pile displacement and peak pile curvature from 400 nonlinear FE analyses for: (a) scenario 1; (b) scenario 3; (c) scenario 5; and (d) scenario 6. 

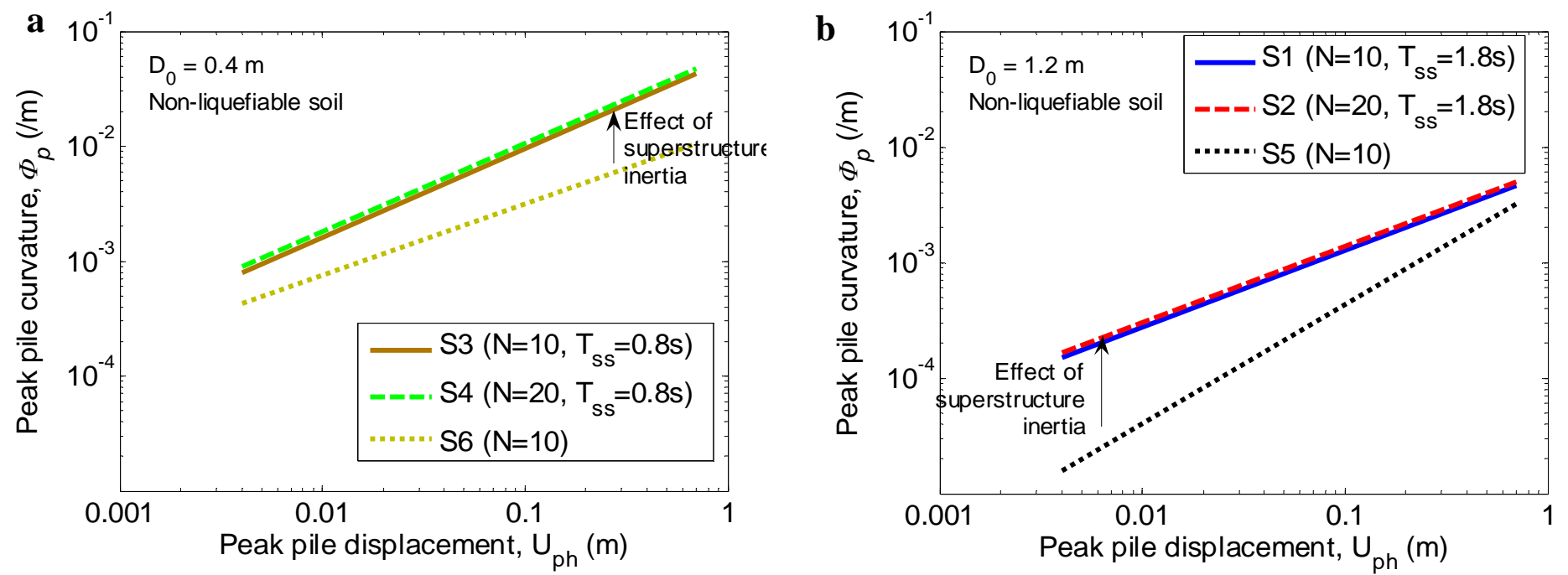

Figure 4: Illustration of the variation in the relationship between peak pile curvature and peak pile-head displacement for different pile and soil conditions; (a) $0.4 \mathrm{~m}$ diameter pile and (b) $1.2 \mathrm{~m}$ diameter pile. 

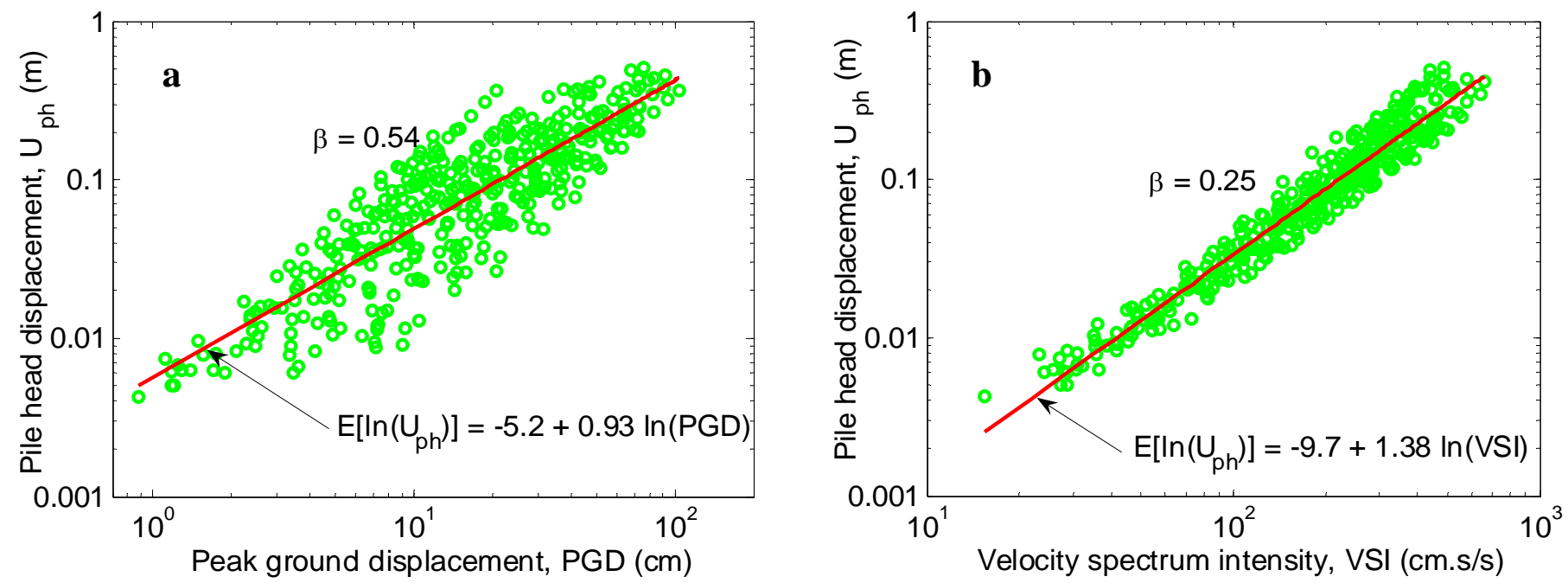

Figure 5: Comparison of EDP-IM scatter plots for: (a) peak ground displacement, $P G D$; and (b) velocity spectrum intensity, VSI, for the 400 analyses in scenario 1. 


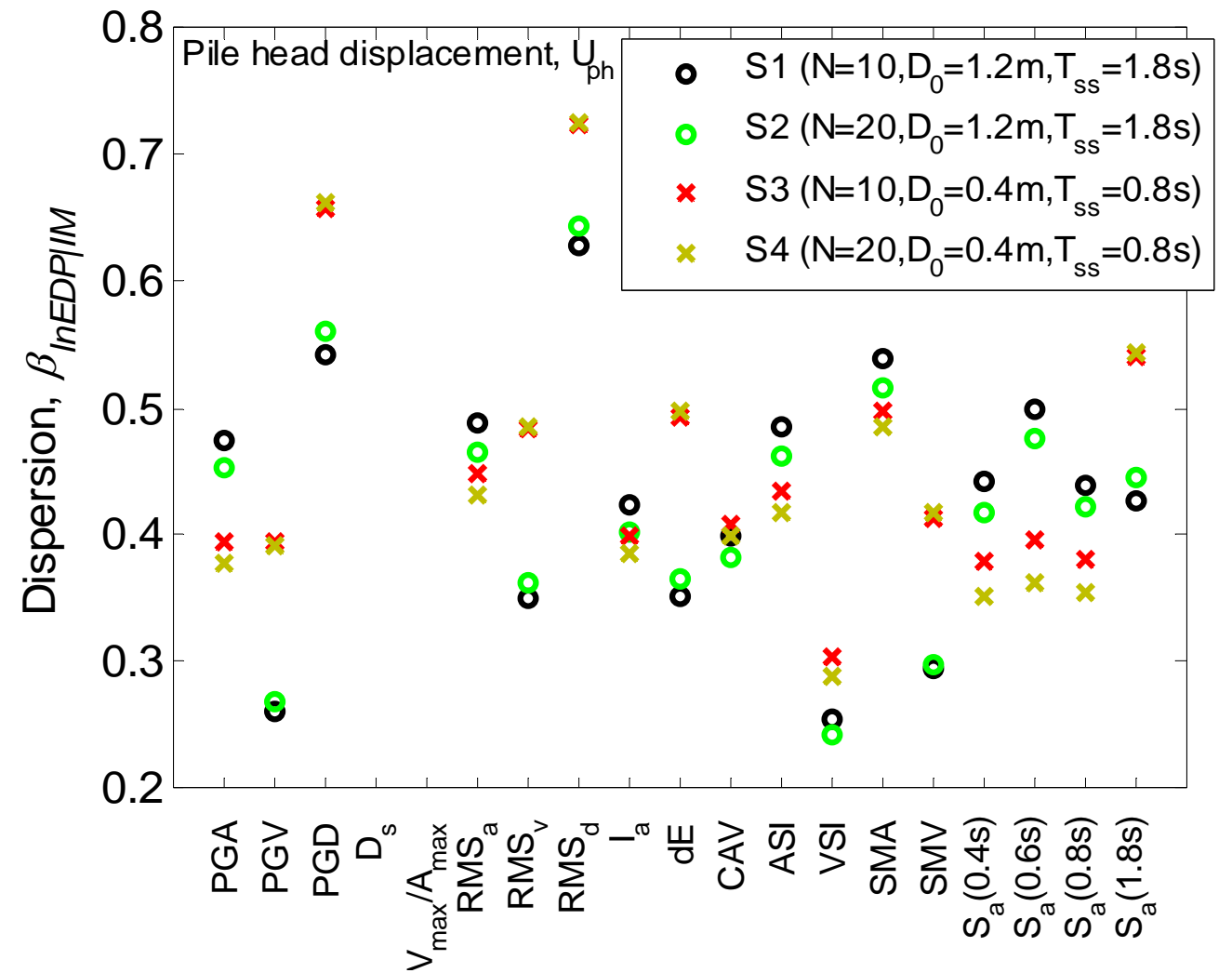

Figure 6: Efficiency of the candidate IMs for the four base scenarios (non-liquefiable soils). 

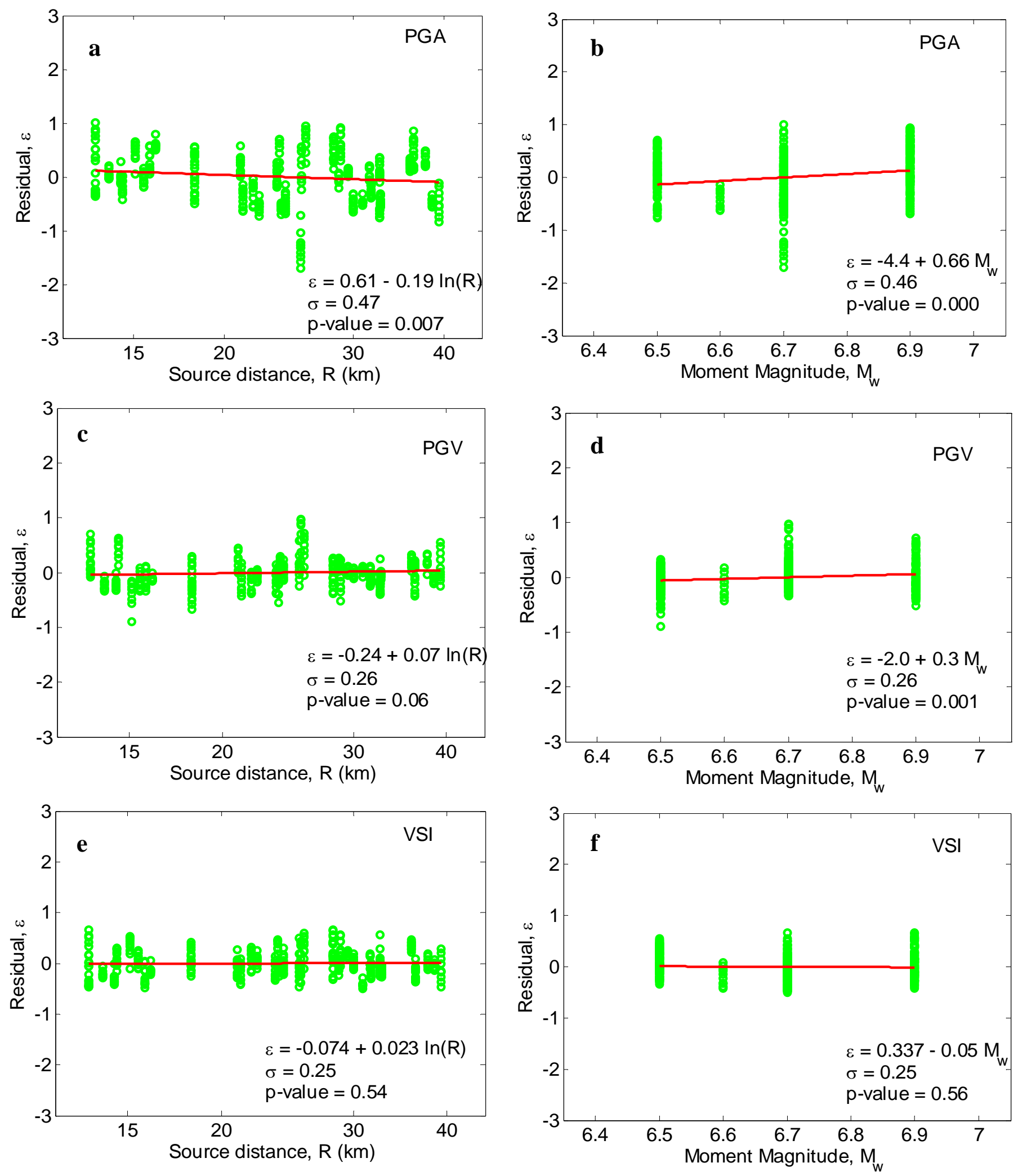

Figure 7: Sufficiency of peak ground velocity, peak ground acceleration and velocity spectrum intensity with respect to magnitude and distance 


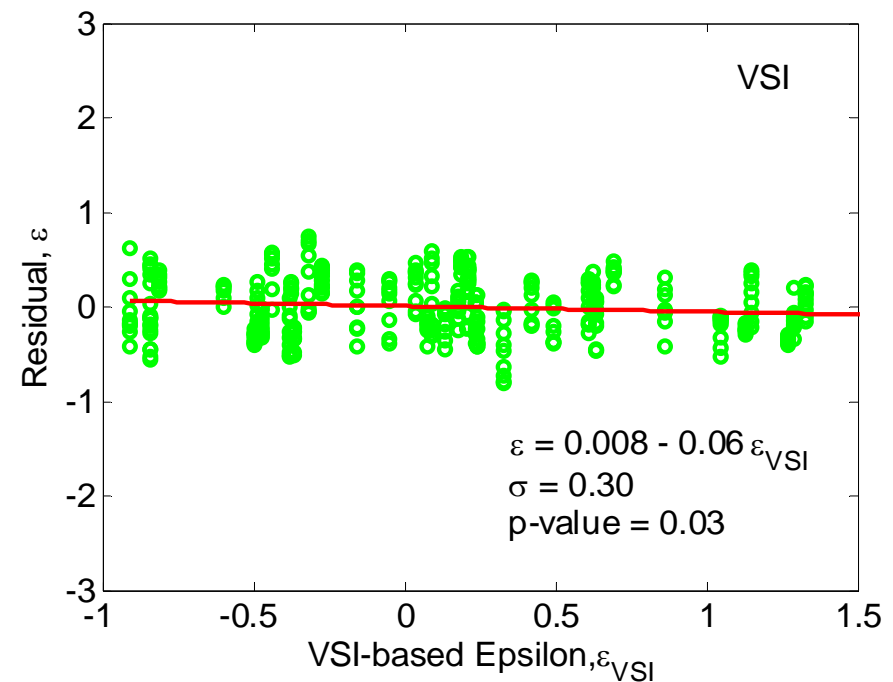

Figure 8: Sufficiency of VSI with respect to the ground motion parameter epsilon. 

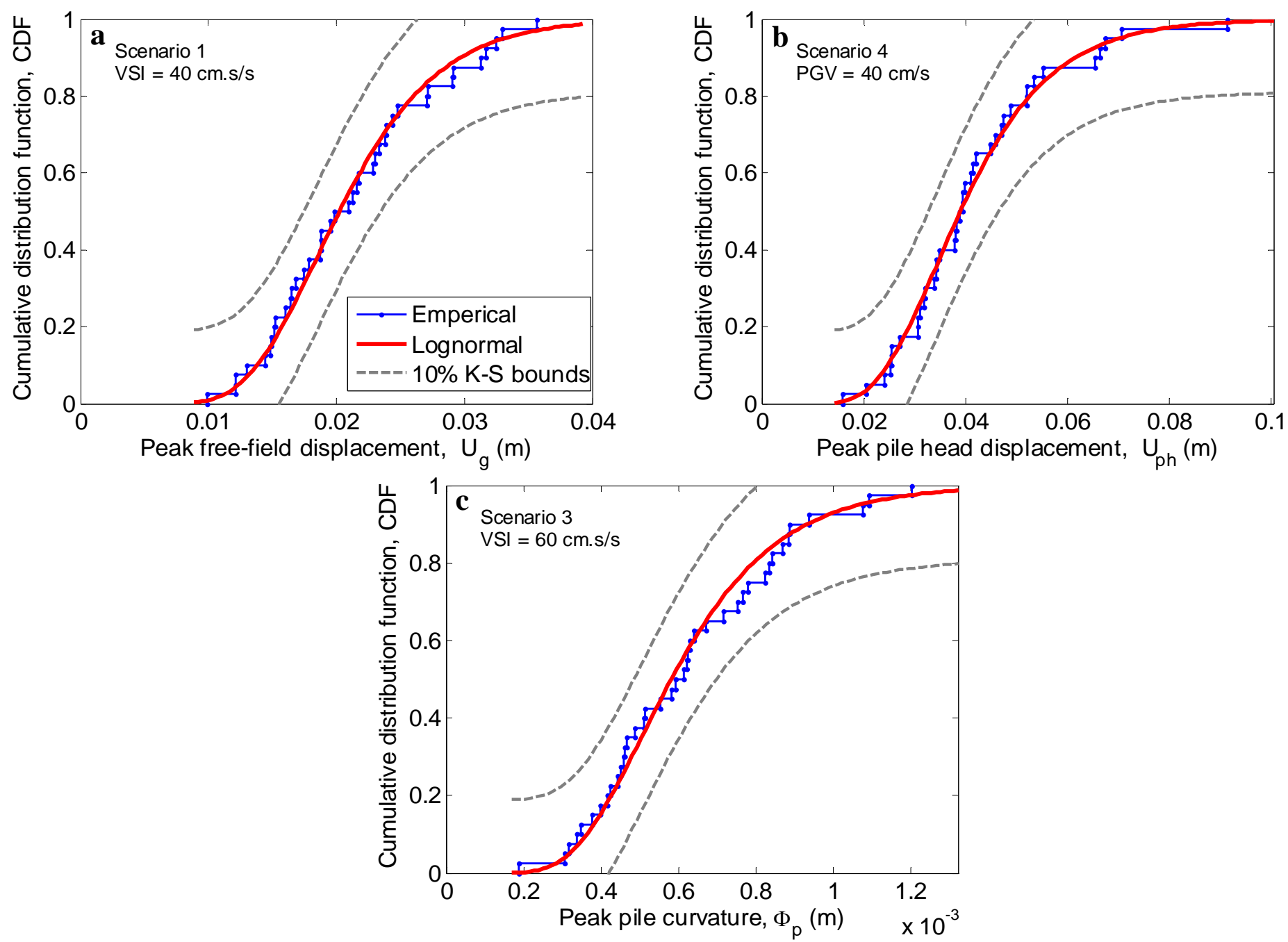

Figure 9: Goodness-of-fit tests for the distribution of: (a) peak free-field displacements; (b) peak pile-head displacements; and (c) peak pile curvatures for various scenarios and levels of ground motion intensity measures. 

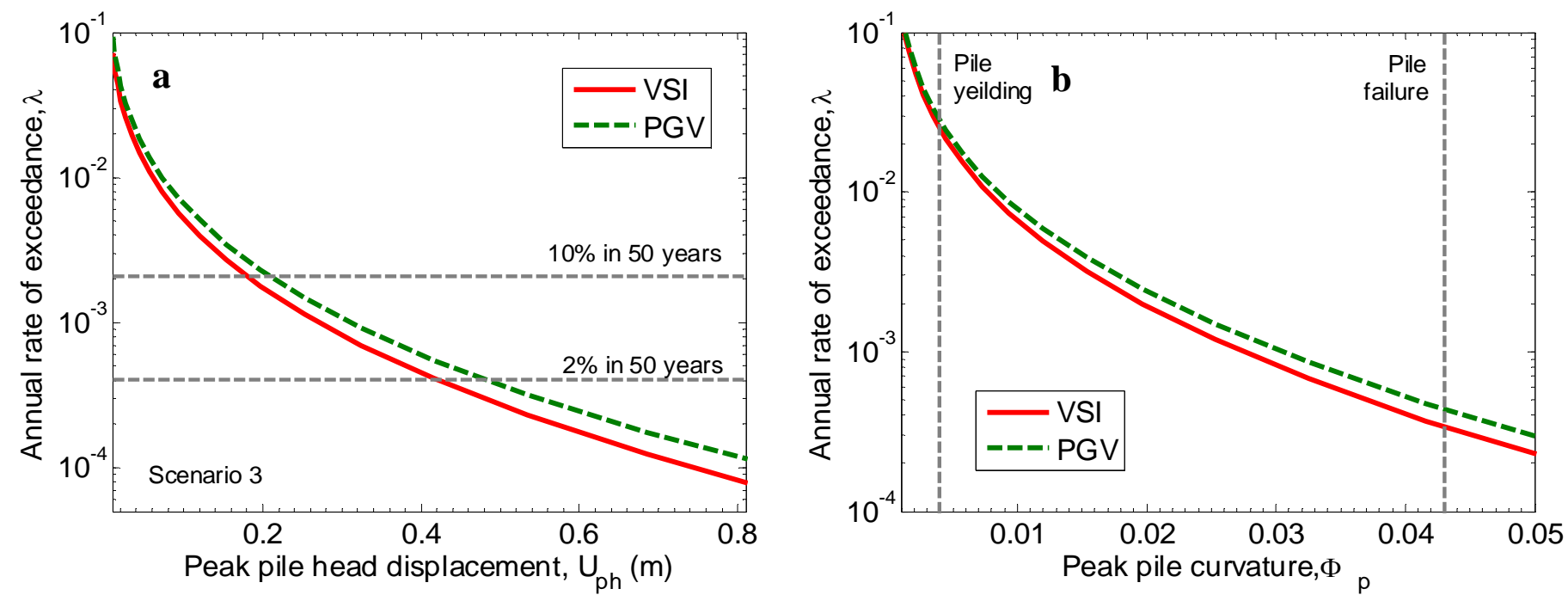

Figure 10: Hazard curves for: (a) peak pile-head displacement; and (b) peak pile curvature using VSI and $P G V$ as IMs (scenario 3). 


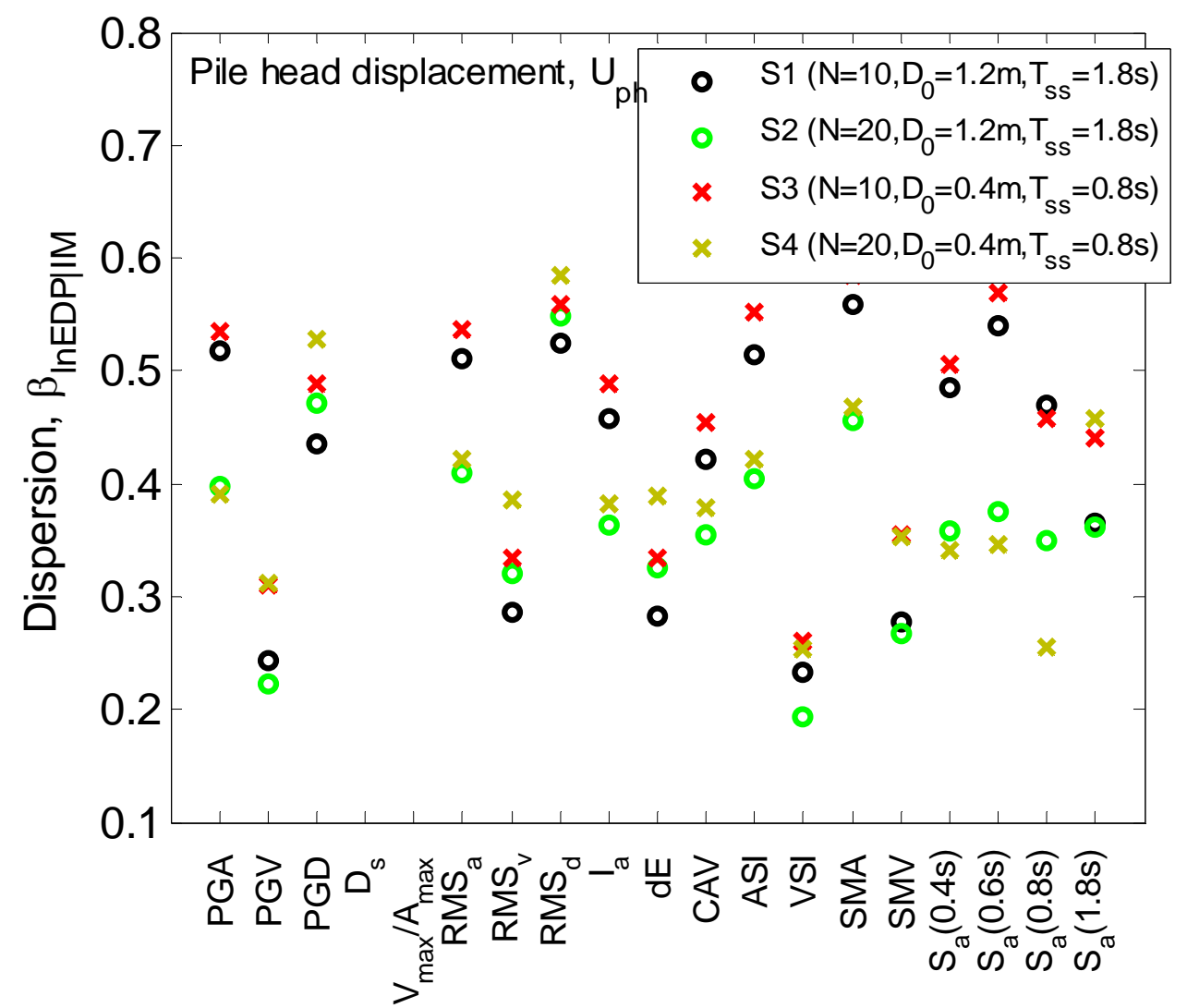

Figure 11: Efficiency of various IMs in predicting pile-head displacement (liquefiable soils) 

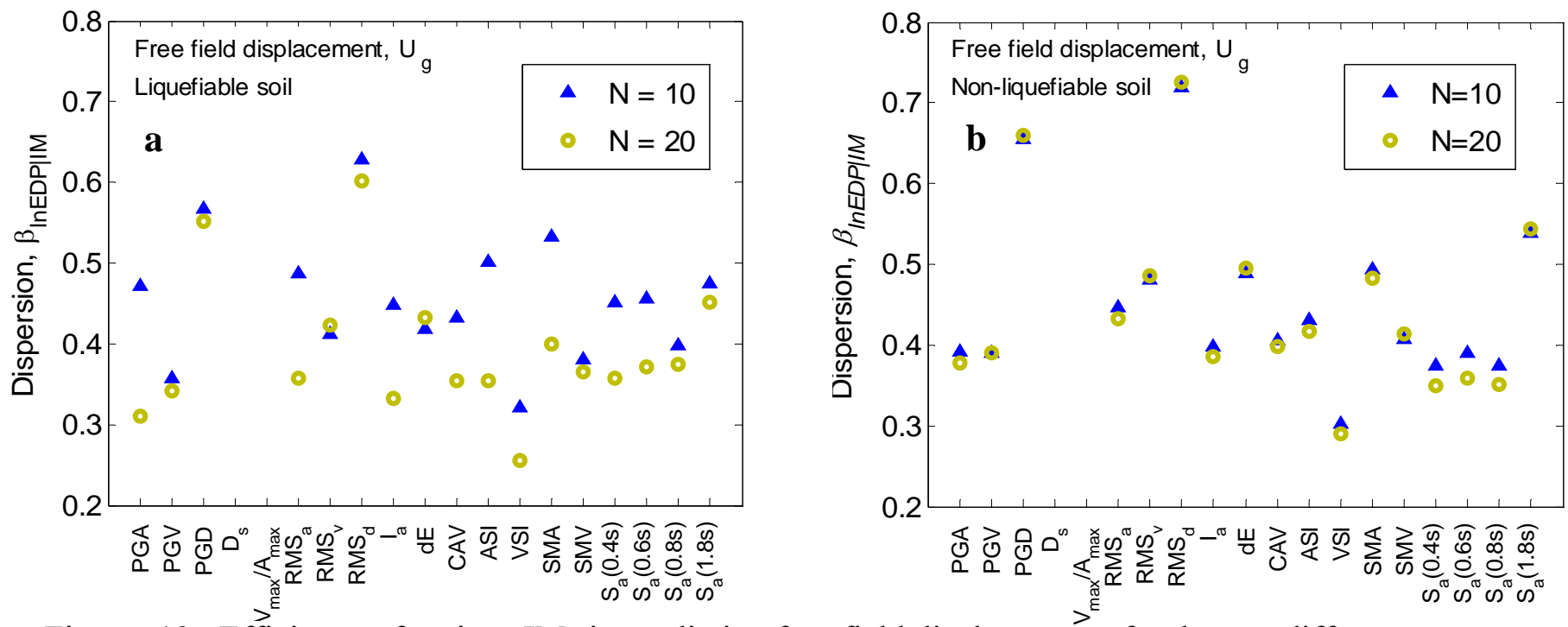

Figure 12: Efficiency of various IMs in predicting free-field displacements for the two different upper layer soil types considered: (a) liquefiable soils; (b) non-liquefiable soils. 

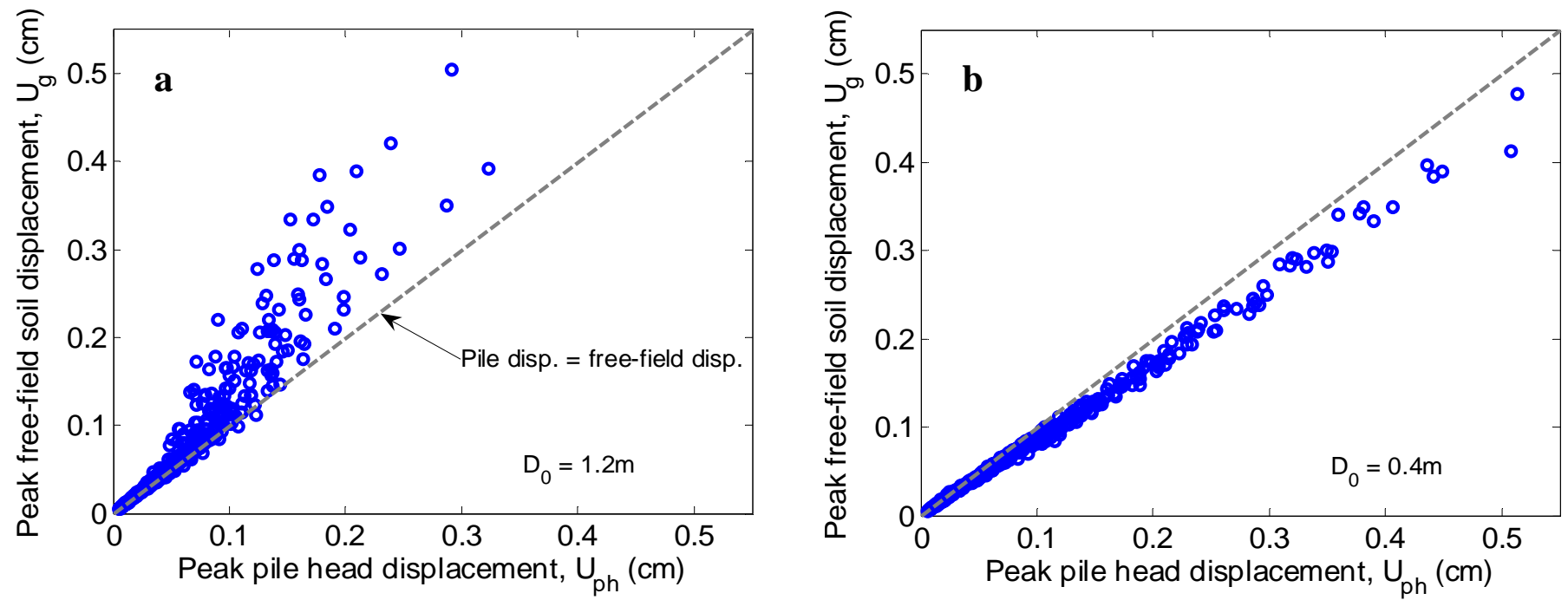

Figure 13: Comparison of relationships between free-field soil and pile-head displacements for (a) $1.2 \mathrm{~m}$ diameter pile and (b) $0.4 \mathrm{~m}$ diameter pile (liquefiable soils). 


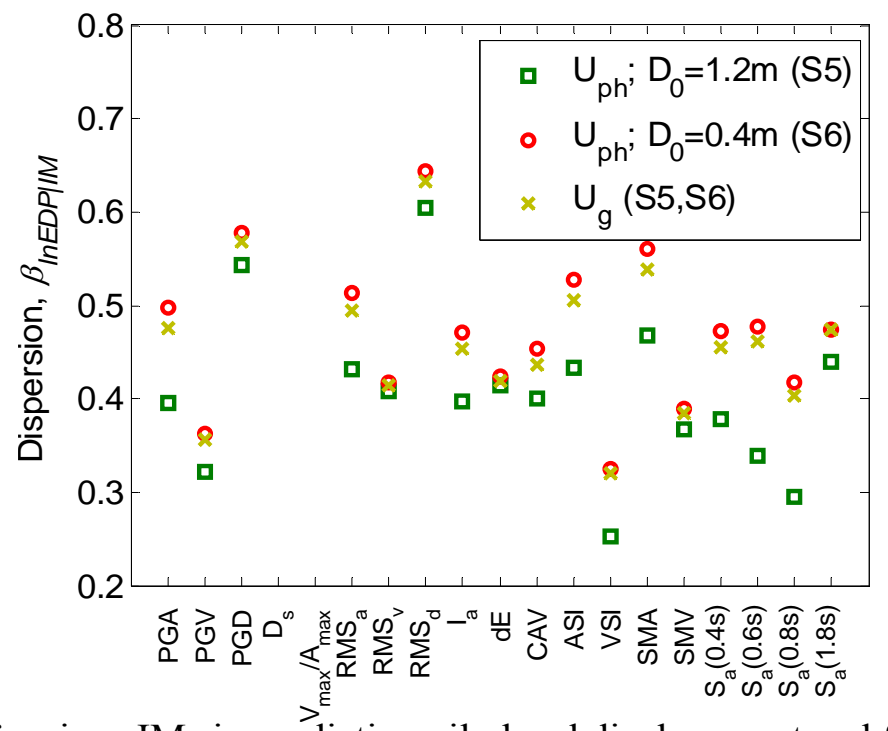

Figure 14: Efficiency of various IMs in predicting pile-head displacement and free-field soil displacement: illustration of stiff-pile and flexible-pile behaviour (liquefiable soils). 